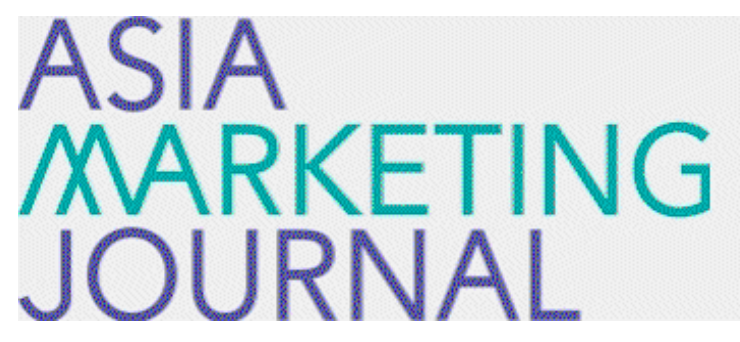

ASIA MARKETING JOURNAL

Volume 20 | Issue 4

Article 1

$1-31-2019$

\title{
Pioneering New Markets
}

Shijin Yoo

Myung Soo Kang

Minjeong Kim

Follow this and additional works at: https://amj.kma.re.kr/journal

Part of the Marketing Commons

\section{Recommended Citation}

Yoo, Shijin; Kang, Myung Soo; and Kim, Minjeong (2019) "Pioneering New Markets," Asia Marketing Journal: Vol. 20 : Iss. 4 , Article 1.

Available at: https://doi.org/10.15830/amj.2019.20.4.1

This Article is brought to you for free and open access by Asia Marketing Journal. It has been accepted for inclusion in Asia Marketing Journal by an authorized editor of Asia Marketing Journal. 


\title{
Pioneering New Markets: A Case study of SevenBräu*
}

\author{
Shijin Yoo** \\ Myung Soo Kang*** \\ Minjeong Kim****
}

This paper reports a case study of SevenBräu, the first company to acquire a license for small and medium scale beer manufacturing in Korea. This study explores how SevenBräu analyzed its consumers, competition, and environment to set its target market and successfully positioned itself to explore new markets in Korea. The company accomplished this through a mixture of marketing strategies with differentiated products and consumer benefits.

SevenBräu has been growing fast and establishing its image as a "high-quality craft beer locally produced in a traditional way" and a "beer with regional characteristics," with young consumers (aged 20 to 35) as the main target. Such remarkable growth of SevenBräu can be attributed to factors such as: (1) product differentiation to satisfy the needs of consumers for taste, flavor, diversity, and freshness, (2) developing brands with regional characteristics and actively communicating its strategy through earned and owned media, and (3) sustainable management, considering both social value creation and environmental performance.

Lastly, this case study presents challenges in the areas of brand management, value delivery network, and communication that SevenBräu needs to address in the beer market that faces increasing competition.

Key words: Beer industry, Craft beer, Consumer trend, Product differentiation, Brand communication

\footnotetext{
* This research was financially supported by Hansung University.

** Professor, Korea University Business School (shijinyoo@korea.ac.kr)

*** Professor, Department of International Trade, Hansung University (mskang@hansung.ac.kr)

**** Doctoral student, Korea University Business School (mkim9@korea.ac.kr), Corresponding Author
} 


\section{Introduction}

Beer is a fermented alcoholic beverage, brewed from malted barley with water, hop, and yeast, through a three-step production process including: first, malting (where raw barley is converted into malt); second, mashing (where malt is made into wort); and third; fermentation/ storage/filtration/ and packaging procedures. If beer is brewed by employing all three steps, it is referred to as mega brewery. In contrast, craft beer is usually brewed from the mashing process, skipping the malting process. The American Brewers Association defines craft beer as beer produced traditionally using ingredients from a brewery with an annual production of six million barrels of beer or less, and less than 25 percent of which is owned or controlled by outside capital.

As represented by new colloquial labels such as "hon-maek (drinking beer alone)" and "home-maek (drinking beer at home)," recently, more and more Koreans prefer drinking in a healthy and convenient way over gulping down "bomb cocktails" with colleagues after work. Consumers, who prefer to drink in the comfort of their own homes or enjoy just a couple of beers in the pub, started looking for various flavors to please their palates. With this increasing demand for variety in beer, more attention is being paid to imported beer or craft beer. According to an analysis by Industrial
Technology Research Center of Korea Development Bank in 2017, the market share of domestic brewers, including Oriental Brewery Co., Ltd. (OB), Hite-Jinro Co., and Lotte Chilsung, decreased from 95.9\% to 91.5\% between 2012 and 2015 in the Korean beer market, while that of imported and craft beer increased (Bae 2017).

In Korea's saturated beer market, competition is getting fierce between local giants, which still maintain high market share; and imported beers, which continue to penetrate the local market. In such a competitive market, SevenBräu is gaining ground as "the first Korean craft beer company" or "the first beer company established in Korea with national capital only, since the country's liberation from Japanese colonial occupation". Also known as the brand whose beer has been invited to the "meeting with entrepreneurs" at the Blue House in July 2017, SevenBräu produces a wide array of beers as a "medium" brewery while also operating franchise pubs. This case study analyzes how SevenBräu created and explored a new beer market by focusing on new product development and innovative marketing strategies.

\section{Korean Beer Market}

\subsection{Products}

The beer industry can be classified into mega 
brewery, going through the three production stages; and microbrewery or craft beer, brewing beer without the process of malting. While mega brewery tailors to a mass market (general consumers), craft beer caters to consumers who demand beers of distinct styles.

Beer can be classified based on the way it is fermented. Specifically, in top fermentation, yeasts form a layer of foam on the surface of the fermenting beer; while yeasts collect at the bottom in bottom fermentation. Top fermentation occurs at warmer temperatures than bottom fermentation and top-fermented beers are darker in color, with stronger flavor and taste. Such beers are generally classified as ales. In comparison, bottom fermentation occurs at cooler temperatures $\left(10^{\circ} \mathrm{C}\right.$ to $\left.12^{\circ} \mathrm{C}\right)$ and produces beers with clean and gentle flavors. The beers fermented in this manner include lager and pilsner. Major breweries of Korea produce lager-type beers, comprising more than $90 \%$ of the world's beers. For example, the best-selling beers produced by Korea's big three breweries: Cass, Hite, and Kloud, are all lager-type beers, which are mass-produced, and target a wide consumer base. Recently, consumers are increasingly interested in foreign beers since more Koreans travel overseas and a wider variety of imported beers are available in the market.

\subsection{Competition}

Korea's beer market faces rapid changes. Large breweries are now challenged by the onslaught of imported beers and microbreweries which are rolling out various products. Sales of imported beers have been steadily increasing. The annual import of beer has also been increasing at the rate of $30.5 \%$ on average since 2011. Roughly 170,000 tons of beer was imported as of 2015 (Trade Statistics by Korea Customs Service 2018). Accordingly, the market share of imported beer was up from $2.8 \%$ in 2010 to 8.4\% in 2015 and accounted for more than $40 \%$, on average, of the sales of major supermarket chains and convenience stores. It is not uncommon to see imported beers sold in bundles at lower prices than local beers. The popularity of imported beers is projected to continue partly because the tariff on beers shipped from the US, EU, and China will phase out after 2018 under the FTA (Choi and Lee 2018).

It is estimated that there are currently about 30 beer importers including Lotte Asahi Liquor, Heineken Korea, and SABMiller Brands in Korea. Also, local brewers like $\mathrm{OB}$ and HiteJinro jumped into the import business, accounting for more than $30 \%$ of total imports. OB distributes and sells 18 kinds of imported beer brands including Budweiser and Hoegaarden, while Hite-Jinro imports French beers like 1664 Blanc; and Japanese beers, such as Kirin 
(Noh 2017).

Other competitors in the beer market include small and medium enterprises (SMEs) and microbreweries. They are distancing themselves from the conventional lager (produced by the local beer giants) by providing beers with distinctive flavors and styles. Leading craft beer brands include SevenBräu, Platinum, and Jeju Beer. They highlight the personality of craft beers, which have different flavors depending on the kind and rate of the ingredients such as malt and hop. SevenBräu and Jeju Beer acquired general licenses, similar to what large breweries have, and they entered the market in 2011.

The popularity of craft beers encouraged large beer companies to build small and mediumsized breweries and produce craft beers. For instance, SSG Food operates a brewery-pub, Devil's Door; and Jinjuham acquired KABREW, maker of craft beer, to jump into the market (Bae 2017). With new players, the local craft beer market grew from KRW 700 million to KRW 20 billion in 2014 (Noh 2017).

Yet, Korea's beer market continues to be dominated by a handful of renowned brewers: OB with $47.7 \%$ market share, followed by Hite-Jinro with $34.9 \%$, and Lotte Chilsung with 9.1\%. With large domestic beer companies still dominating the market, the South Korean credit rating agency, NICE Information Service, considers Korea's beer industry as a mature market with very low growth potential (Choi and Lee 2018).

\subsection{Channels of Distribution}

In the domestic market, beer is distributed from breweries to liquor wholesalers, retailers, and finally, consumers. Imported beers go through the same distribution channels, and only licensed distributors can participate in the market. Beers can be divided by their use and should be labeled accordingly such as "For home use," "For large stores," and "For dutyfree shops." Additionally, products for home and large stores should be labeled with a warning notice: "Not allowed to be sold in restaurants or bars." In comparison, micro brewed beers need not to be divided based on their purpose; they can be sold directly to consumers or via wholesalers. Since producers who hold only brewing license need to go through wholesalers and retailers to reach consumers, it is crucial for them to manage distribution channels efficiently.

Domestic beer breweries are obligated to report production cost, according to which, taxes are imposed. It is prohibited to sell the product at a lower price than the factory price; and prices are set by adding sales management cost and profits to the factory price. By contrast, imported beers are required to be reported based on the import price, and imposed taxes are lower than those of domestic beers. This implies that imported beers have a relatively freer distribution structure than domestic beers (Choi 2018).

Most Korean beer producers have subsidiaries 
to transport products to around 1,200 wholesalers throughout the country (Lee 2018). Recently, various types of distribution channels have been utilized including large supermarket chains importing beer in collaboration with overseas breweries and directly selling to consumers (so called "mart beer"). However, the market of entertainment spots is still dominated by large domestic breweries, in association with general liquor wholesalers, making it difficult for sellers of imported beers to reach this particular market. Imported beer and craft beer brands are expanding by having their sales force visit the bars and restaurants to increase distribution channels. For instance, a wider variety of beers are available in the streets of Hongdae, Daehakro, Gyeongridan-gil; and the area around Gangnam station, which are frequented by young consumers. SevenBräu also operates gastro pubs (which deal with craft beers) mainly around the Seoul metropolitan area, to explore new markets.

\subsection{Consumer Trends}

A new drinking culture among consumers is also driving changes in the competitive landscape of the beer industry. Recently, Koreans increasingly prefer drinking in a healthy and convenient way over gulping down "bomb cocktails" with colleagues after work. This new generation of health-conscious consumers shows preference for low alcoholic drinks like beer, which they can enjoy drinking without worrying too much about their health. These consumers are more interested in imported beers and craft beers than in the conventional products of domestic beer companies. In short, consumers increasingly want diversity and high quality in beer.

This change of tastes for beer appears to be influenced by changes in the country's food consumption culture. During the 70s and 80s, when sugar and carbs were consumed in large quantities, consumers wanted conventional beer recipes; but in the era of "USD 30,000 per capita income," people desire new flavors to suit their increasing consumption of protein. While the large domestic beer companies are sticking to old recipes, craft beer and imported beer brands are responding to market changes to satisfy consumers' needs.

Consumer segments are also becoming diverse. There are so-called "For Me" consumers, who give up marriage or having a baby; and lead a self-centered life style without worrying about what other people would think. They value their health more than anything else and are willing to spend money on leisure and other interests. Along with this trend, the number of people "who drink beer alone," without the need to care about others, is increasing as well. According to a recent survey, people in their 20s who enjoy drinking beer alone, do drink alone, on average, 1.66 times a week; which is once out of every three times they drink (Lee 2016). To cater to these one-person households, 
an increasing number of differentiated highquality products are appearing in the beer market.

Changing tastes of consumers are represented by interests and preference for imported beers over domestic ones. Consumers do not choose imported beer just because they taste better; consumers are highly influenced by the brands. In a blind experiment, participants rated domestic beer the highest in terms of in taste; but showed preference for imported beers when they became aware of the brands (Cho et al. 2014). This result indicates that new groups of consumers, such as "For Me" people or those “drinking beer alone," consider not only quality but also external factors like brand names.

\section{SevenBräu - Pioneering New Markets}

\subsection{History}

CEO Kang-Sam Kim, the founder of SevenBräu, was born in Gochang, Jeollabuk-do, and started a custom tailor shop in his twenties. Later, he expanded his business to restaurants and craft beer pubs. When the license for making small scale beer was introduced, he shifted to the beer market. In 2003, the company opened a craft beer pub, Trains, in Seoul Station Complex. In 2005, it opened the pub SevenBräu in the 7th floor of a building near Balsan subway station. Later in 2011, SevenBräu became the first microbrewery in Korea to get a general license for brewing beer, following large domestic breweries including OB, Hite, Isenbeck, and Cass. Then the company started selling draft beer and distributing to large supermarket chains such as HomePlus and Lotte Mart in 2012; providing canned beer for the military in 2014; distributing 330ml bottles to HomePlus, Lotte Mart, and Emart and also exporting bottled beer to Hong Kong and China as well as canned beer to Saipan in 2015. In 2016, SevenBräu became a sensation when it marketed beers named after regions of Korea, such as "Gangseo," "Dalseo," "Jeolla," and "Seocho." Its popularity shot high, and its supply was temporarily in short supply after being served at the Blue House banquet (where the nation's business people were invited) in 2017. The company started to export to the US in 2018. Currently, SevenBräu operates two breweries in Hoengseong, Gangwon Province. In 2018, the company established Yangpyoung Branch to open a "leisure-camping culture town" factory where visitors can enjoy leisure activities including camping while drinking high-quality craft beer. Bottled beer products, "Han River," "Seoul," and "Yangpyeong," are produced in this factory. Headquartered in Gangseo-gu, Seoul, the company consists of several teams for order, sales, and site management. For the past five years, sales increased from KRW 3.3 
billion in 2014 to around KRW 6 billion. The company aims to achieve KRW 13 billion in sales in 2018 through the operation of additional breweries and aggressive marketing efforts. SevenBräu boasts of an annual capacity of 2,400 $\mathrm{kl}$. of beer, the second biggest beer production capacity as an SME. The company uses malt, the main ingredient of beer, provided by German company Weyermann, and hops from US and Europe suppliers via pre-contract. The natural bedrock water from Gangwon Province, Korea is used for the fermentation process.

\subsection{Targeting and Positioning}

SevenBräu believed that to survive harsh competition with large domestic breweries and imported beer brands, it needed to produce a variety of beer products with distinct taste and flavor in small amounts, focusing on a precise segment of consumers. Based on this understanding, the company targeted college students, young office workers, "For Me", and "Gold Miss" groups who, at ages between 20 and 35, were leading the new trends of "drinking alone" and "drinking at home." Its second target group was "Active Seniors," who prioritized health and tried to live young. SevenBräu planned products to provide new value for these specific market segments. The company saw a lack of value in the existing beer products for such consumer groups and a desire for new kinds of beer among these consumers.

Though domestic consumers put priority on a crisp and refreshing feeling as associated with beer, the main options for them appeared to be the limited choices of beers offered by the three biggest domestic breweries; and imported beers, which have a disadvantage in terms of freshness (due to long transportation) despite the variety of choices they provide. SevenBräu positioned itself, in the minds of consumers as "local high-quality craft beer produced in a traditional way." As shown in $\langle$ Figure 1 , the company aimed at positioning itself as a brand which provides a plethora of products, not just conventional lager; and at the same time minimized the transportation distance of local production to keep the products as fresh as possible (even fresher than bigname industrial lagers).

SevenBräu reinforces its positioning of highquality combined with freshness, through the production process. Their beers go through the fermentation process using yeast based on the natural bedrock water from Gangwon Province and cold-chain distribution after being put in the container ${ }^{1)}$ without filtering or heat-treatment. SevenBräu is being touted as "real" beer, even fresher than "draft" beer, since the beer produced

1) This means after fermentation, before filtering, and filling the kegs with fermented beer in the beer production process. 


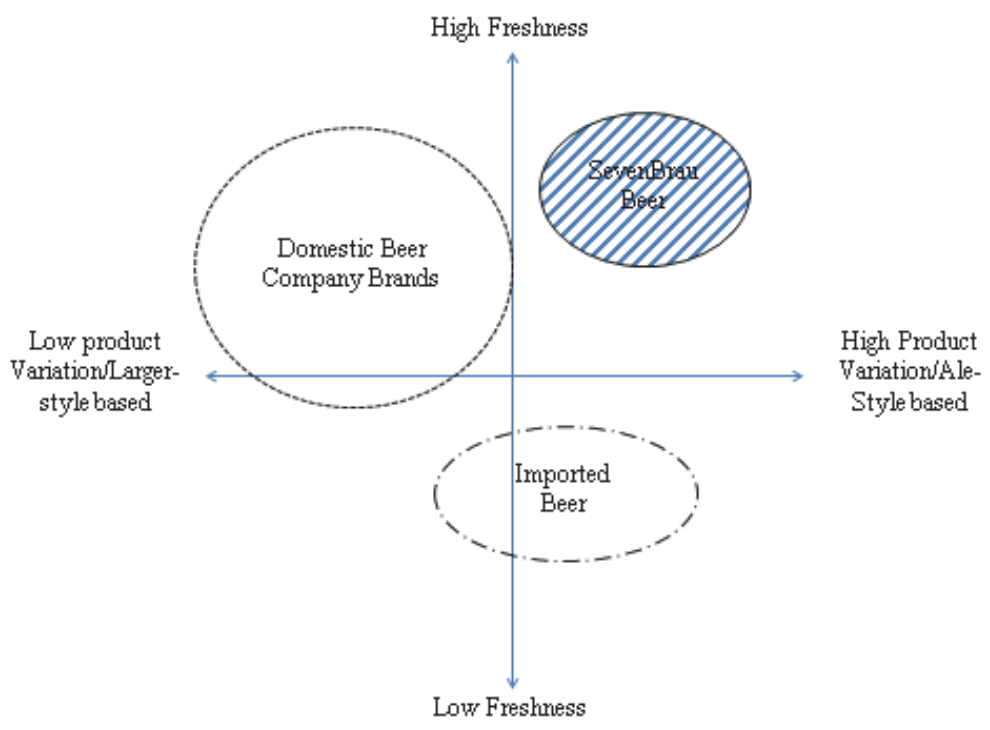

and distributed in this manner is more nutritious as it contains living yeast.' Moreover, SevenBräu produces pilsner and ale beers, as well as lager-type beers. In particular, it has presented a wide assortment of ale beers to satisfy different tastes of consumers. The diversification of its products has positioned SevenBräu differently from the big three domestic breweries.

\subsection{Products}

As previously mentioned, SevenBräu produces both ale-style and lager-style beers. The alestyle line of products includes India Pale Ale (IPA), wheat beer, Weizen, Imperial IPA, Stout, Mild Ale, and Korean Pale Ale. The first ale product made by SevenBräu is IPA, which enjoys distinct taste and flavor of an ale-type beer by using more hop than the traditional pale ale. SevenBräu IPA has the characteristic flavor of caramelized malt, cascade orange and tangerine, with medium-body, high alcohol content of 5.5\%, and bitter taste. Weizen, made from a blend of barley malt and malted wheat, has a hazy pale gold color, gentle flavor, and a distinct fruity aroma. A light vanilla flavor and an alcohol content of $4.2 \%$ make it a good casual and fresh choice of beer. Imperial IPA is a "double" beer, which contains higher amount of malt and hop, is characterized with high alcohol content $(7.0 \%)$, has a full body with caramel flavor, and a balance of sweet

2) Yeast contains four times more protein than cheese and other nutrients such as natural Vitamin B groups, minerals, Co-enzyme A, polysaccharides (Glutathione, Glucan, Mannan etc.), 16 amino acids, selenium, and dietary fiber. 
and bitter taste. Stout, using roasted barley, has a characteristically dark brown color and a burnt flavor with chocolate or coffee aroma. It has an alcohol content of 5.0\% and tastes stronger and thicker than ordinary ale. On the contrary, mild ale, being mildly hopped, has a less bitter taste and a fruity aroma. It is an orange-colored beer with thin and fluid creams. Lastly, Korean Pale Ale, a Korean interpretation of the IPA, has a weak bitter taste and a floral aroma of hop.

The lager-style line of SevenBräu products includes Pilsner, Fake Lager, and Red Ginseng Lager. Pilsner is a Czech-style lager and has a clean and mild bitter taste from Saaz hop. This dark gold colored beer has a well-balanced flavor that elicits a refreshing feeling and a taste of bitterness. Fake Lager, unlike general lager beers, has a tint of reddish brown and a caramel aroma; it has a clean taste with a light bitterness. Red Ginseng Lager is produced by adding Korean red ginseng essence during the fermentation process making it a healthier choice with immunity-strengthening and antiaging effects. Other than that, regional beer products, such as "Gangseo," "Dalseo," "Jeolla," and "Han River" are produced, attracting great attentions from the public. The characteristics and production methods of each product are summarized in 〈Table 1〉.

\subsection{Branding}

SevenBräu is a combined word of "Seven," which means the six ingredients of beer hop, male, yeast, water, herb, and spice - and craftsmanship, and "Bräu," meaning brewery in German. The brand name, SevenBräu means

〈Table 1〉 Products of SevenBräu

\begin{tabular}{c|c|c|c}
\hline Products & Color & Form & ABV (\%) \\
\hline IPA & dark brown & Real/Draft/Can/Bottle & 5.5 \\
\hline Weizen & cloudy gold & Real/Bottle & 4.2 \\
\hline Imperial IPA & deep sunset & Real/Bottle & 7.0 \\
\hline Stout & black & Real/Bottle & 5.0 \\
\hline Mild Ale & brown & Real & 4.2 \\
\hline Korean Pale Ale & Light brown & Bottle & 4.6 \\
\hline Pilsner & gold & Real/Draft/Bottle & 5.0 \\
\hline Gangseo & Light brown & Draft/Bottle & 4.6 \\
\hline Dalseo & cloudy gold & Draft/Bottle & 4.2 \\
\hline Jeolla & gold & Draft/Bottle & 4.5 \\
\hline Han River & cloudy gold & Draft/Bottle & 5.2 \\
\hline
\end{tabular}

*ABV: Alcohol by volume 
a "brewery where 'seven-star' beer is produced." Another meaning of SevenBräu is a "beer factory on the $7^{\text {th }}$ floor" referring to the craft beer pub opened by the CEO Kim near Balsan subway station. SevenBräu, the first company to acquire a license for making small and medium scale beer in Korea, produces premium beers with original technology in Korea. Within this context, SevenBräu is making efforts to connect the concepts of pioneering spirit, legitimacy, and craftsmanship to its brand.

One of the most distinctive characteristics of SevenBräu brand products is that they are named after the regions of South Korea. As shown in $\langle$ Figure 2$\rangle$, there are products such as Gangseo Mild Ale, Dalseo Orange Ale, Jeolla Ale, and Seocho Wheat, which are differentiated from each other and maintain region-friendly images. Gangseo is mild ale with $25 \mathrm{IBU}^{3)}$ and has a distinctive rich nutty malt flavor and citrus aroma of orang and mango. Its label shows Gimpo International Airport, one of the areas of attraction in the region. Dalseo, made by fermenting a blend of barley malt and malted wheat, has a wheat flavor and fresh aroma of orange with a gentle vanilla note. Dalseo illustrates the sunset of Eworld in Daegu on its label. Jeolla is traditional ale and has a cool and refreshing flavor with a touch of citrus aroma like grapefruit and lime, making it a favorite summer beer. Its label, designed by a female local painter from Jeolla Province, also highlights region-friendliness and coolness through a copy in Jeolla dialect. Seocho is a wheat beer with a distinct banana flavor. These products position themselves as representative local beer brands winning the "2018 Korea First Brand Awards" (Go 2018). According to the craft beer law amended as of April 1 of 2018, the capacity of beer manufacturing tanks is increased from $75 \mathrm{kl}$. to $120 \mathrm{kl}$., making it possible to supply to brand retailers. The first beer designed to match the deregulated standard, Han River, produced by SevenBräu Yangpyeong Co., Ltd., is a wheat ale with alcohol content of $5.2 \%$. On its label is inscribed a young couple enjoying the famous night landscape near Sungsan bridge at the end of the day. For the sole purpose of reaching a wider customer base, Han River was released, at a $21 \%$ lower factory price than other craft beers, to family and large discount chain stores. Also, in an effort to make more environmentally friendly products, the company introduced slim low-carbon type bottles (82 g.), 27\% lighter than the existing bottles (300 g.). Lastly, Seoul is a traditional ale beer with rich and sweet flavors of caramelized malt and a fresh hop aroma; its alcohol content is 5.0\%. Its label represents the image of Seoul, showing symbolic

3) IBU (International Bitterness Unit) is a gauge of beer's bitterness and measures the milligrams per liter of Iso-AlphaAcid found in a beer. 
〈Figure 2〉 SevenBräu's Region-Labeled Products

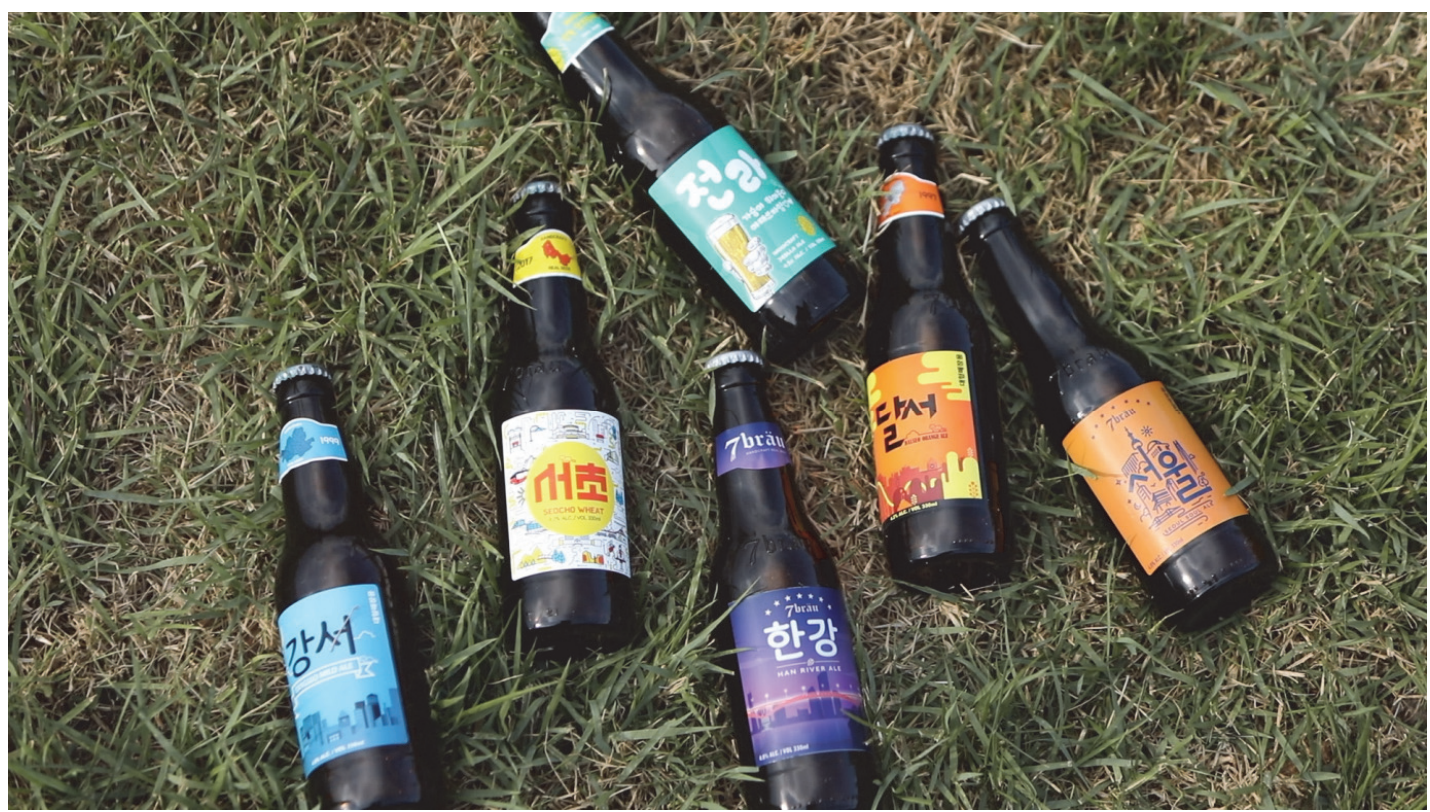

places such as Namdaemun Gate, N Tower, National Assembly, 63 Building, and Lotte World Mall.

\subsection{Distribution and Sales}

In the liquor market, the functions of production and distribution are separated. To overcome distribution obstacles and compete with subsidiaries of large domestic beer brewers, SevenBräu implemented differentiated distribution strategies at the wholesale and retail centers. For first-line customers (wholesalers), the company established connection by cooperating with and explaining products to CEO and sales people and contacted wholesalers by regions to provide products to a number of wholesale shops, chain stores, and Korea's Agricultural Cooperative Federation. Also, the company distributes to second-line customers, such as convenience store (Seven Eleven, CU), large supermarket chains (HomePlus, Lotte Mart), pubs, world beer specialty bars, and restaurants in streets near Hongdae, Gyeongridan-gil, and Gangnam subway station, which are frequented by young people. Starting from 2018, the Liquor Tax Law was amended to allow craft beers to be distributed and sold in large supermarket chains or convenience stores, making it possible to provide SevenBräu beers to end-consumers through diverse channels. Furthermore, the company plans to increase the number of SevenBräu pub franchises, which is 15 as of August 2018. 
The domestic beer market is stagnant since it is at the maturity stage, and the overseas market is already filled with regional beers of each country. It is not easy to sell Korean beers overseas (Choi and Lee 2018). However, SevenBräu is not hesitant to go global. It has become the first Korean craft beer brewery to export to the US market, home to craft beers, and is now selling beers throughout LA and Las Vegas (Lee 2017). The first export was around 20,000 bottles of IPA and Pilsner, representative beers of SevenBräu, and the amount of export has been increasing gradually.

\subsection{Communication}

SevenBräu uses both earned media utilizing social network services (SNS) and owned media through in-house communication channels more actively than paid media such as traditional TV commercials. Also, the company depends on a communication strategy to raise brand recognition and establish reputation through direct methods such as word-of-mouth or other promotional activities instead of direct advertising of its advantages. For example, SevenBräu beer was served at the Blue House banquet where leading business people were invited in July 2017 (Ahn 2017). This event was exposed in the media pushing up the sales of Gangseo beer by $42 \%$ from the previous week (Woo 2017).

Thanks to such favorable media exposure, SevenBräu was able to pay 5\% dividend to its crowd funding ${ }^{4)}$ investors in 2017. At the time of investment, the enterprise value of the company was assessed at KRW 10 billion, but it is estimated to have grown dramatically due to indirect promotion effect (Woo 2017). In addition, SevenBräu Yangpyeong Co., Ltd. was assessed at KRW 9 billion and received KRW 500 million in crowd funding investment for its establishment in 2018.

SevenBräu is also committed to transferring meaning to its brand to enhance brand assets. Already positioned as a customized beer company communicating with regional customers, SevenBräu attempts to strengthen its ties with consumers in the local community by making donation and lending support to community events. The company also concluded a business agreement between the Korean Film Actors Association and SevenBräu pubs; and the phrase of "officially designated by the Korean Film Actors Association" is inscribed on its products and pubs, giving premium image to the brand. Both parties agreed that they will cooperate in developing brands in the future (Hwang 2018). 4) Crowdfunding is the practice of funding a project or venture by raising small amounts of money from a large number
of people, typically via the Internet and mobile network. 


\section{Success Factors and Future Challenges of SevenBräu}

\subsection{Key Success Factors}

Key factors of SevenBräu's success include its product differentiation, brand communication, and sustainable management (Kotler and Keller 2012, Narver and Slater 1990). First, SevenBräu sells products which take distinctive positions in the minds of consumers, including Red Ginseng Lager, which has Korean characteristics, or beers named after regions like Gangseo or Jeolla. It goes further to create a differential advantage as a premium beer with better quality than other beers, by developing unique taste and flavor and guaranteeing freshness as a locally produced beer.

Second, SevenBräu engages in active communication with consumers. The company focuses more on viral marketing to achieve natural exposure online, than on conventional advertising, and creates and provides diverse contents with storytelling about the products via social media. The first regional beer of Korea, Gangseo beer, for example, inspired word-of-mouth among local consumers by applying the real skyline of Gangseo District, which residents are familiar with, in its label design. This way (using local color and stories that are appealing to consumers) is more effective in establishing brand recognition and shaping the brand's image than simply providing information or using direct appeal (Akpinar and Berger 2017). As such, the company's communication efforts and off-line grass root marketing, including the operation of pubs, create synergy to complement the weaknesses of SMEs and achieve high brand recognition and favorable brand image in a relatively short period of time.

Third, the company's philosophy of sustainable management, considering social and environmental performances, as well as financial performance, helps create a favorable attitude among consumers. All employees of SevenBräu are regular employees, which was one of the important social performances that were considered to be selected as the toasting drink of the Blue House banquet. SevenBräu is also known for its robust welfare system including the support of housing deposit for young workers (Lee 2017). When Yangpyeong factory was completed in 2018, the company held cultural and camping events and built a cultural town where people can enjoy craft beer while camping. This is a good example of SevenBräu's effort to make the community and business happily coexist (Cho 2018). Besides, SevenBräu is the first craft beer brewery to use lighter bottles to contribute to reducing carbon emission. It is believed this consideration of "triple bottom line," which is a necessity for sustainable management, has played a key role in enhancing the image of the company as well as the product. 


\subsection{Future Challenges for SevenBräu}

SevenBräu faces several hurdles as it aims to be a national, and ultimately, global company like Boston Beer Company, best known as the maker of Samuel Adams. SevenBräu is reaching out to consumers with differentiated products and brands with regional characteristics. However, as other small and medium-scale breweries are also releasing a variety of beers with creative and sophisticated brands, competition in the craft beer market is becoming more intense. Korea Craft Brewery, one of its rivals, is distributing craft beers named after regions like "Haeundae," "Yeosu," and "Pyeongchang," while The Booth sells high-quality ales named after places, such as "Daedonggang Pale Ale." Korea Craft Brewery produces a 40-plus variety of beers and The Booth is actively involved in creating a new cultural trend by entering the US market and holding beer festivals in promoting the brand. Jeju Beer successfully ran a popstore in Yeonnam-dong, Seoul, presenting a marketing model for other breweries.

It is important for SevenBräu to position its brand and products as that of a representative craft beer in the minds of consumers to sustain its growth in the beer market. To this end, brand hierarchy management and brand reinforcement are necessary. Strategies for the short and long terms have to be established on how the brand image is to be delivered to consumers by brand hierarchy; specifically, corporation (e.g., SevenBräu), product group (e.g., IPA), and product (e.g., Gangseo Mild Ale). In addition, it is necessary to discuss how brand elements (to which opinion leaders would be responsive, such as "high quality," "diversity," and "innovativeness") should be added to counter the negative implications consumers might have, in association with the brand's present image as a "locally produced

〈Figure 3〉 Competing Products of SevenBräu
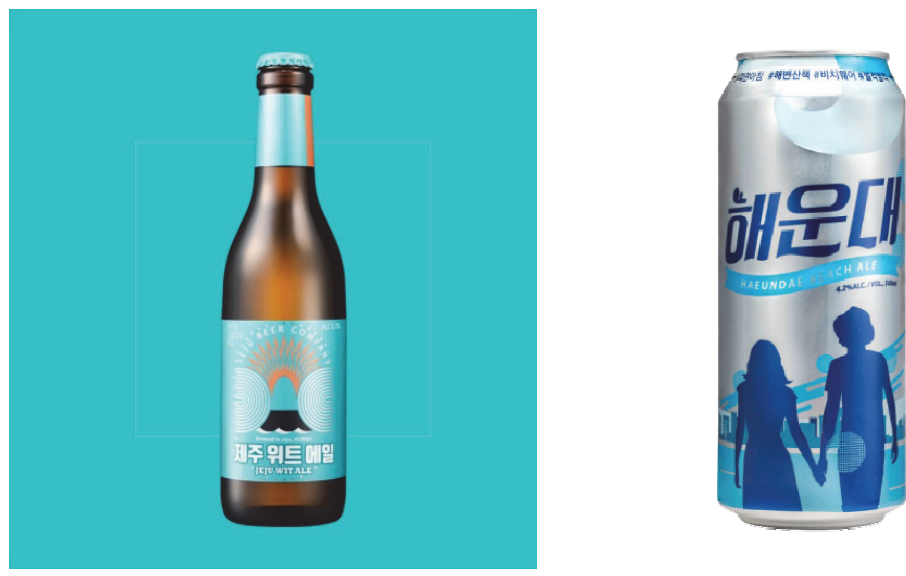
regional based beer." For example, in shaping the brand image, it would be a critical decision to plan a totally new series of products instead of simply expanding the regional brand lines, Gangseo, Dalseo, Jeolla, Seocho, among others. Another important challenge is the seamless distribution of a wide array of products in domestic and overseas markets. This requires expansion of manufacturing facilities and maintenance of distribution networks. In July, 2018, SevenBräu had a completion ceremony of Yangpyeong factory, where the $3^{\text {rd }}$ and $4^{\text {th }}$ breweries are scheduled to operate; in addition to the $1^{\text {st }}$ and $2^{\text {nd }}$ breweries in Hoengseong. The addition of a fifth brewery is currently under discussion. The $3^{\text {rd }}$ and $4^{\text {th }}$ breweries in Yangpyeong are expected to reach an annual production of 1,440 tons each, with estimated annual sales of KRW 10 billion per brewery. The fifth brewery will be established in Daegu, with target date of operations in 2019.

To effectively implement brand and productrelated strategies that are differentiated from large breweries or imported beer companies, it is critical for SevenBräu to have manufacturing facilities and operational competencies in place. Also, the distribution channels, currently concentrated on a discount store, should be developed into a value delivery network by including a wider array of discount stores, convenience stores, and big pubs in main areas to facilitate reaching out to more consumers.

Regarding communication strategy, it is necessary to select appropriate channels and

〈Figure 4〉 Panoramic View of SevenBräu Yangpyeong Factory

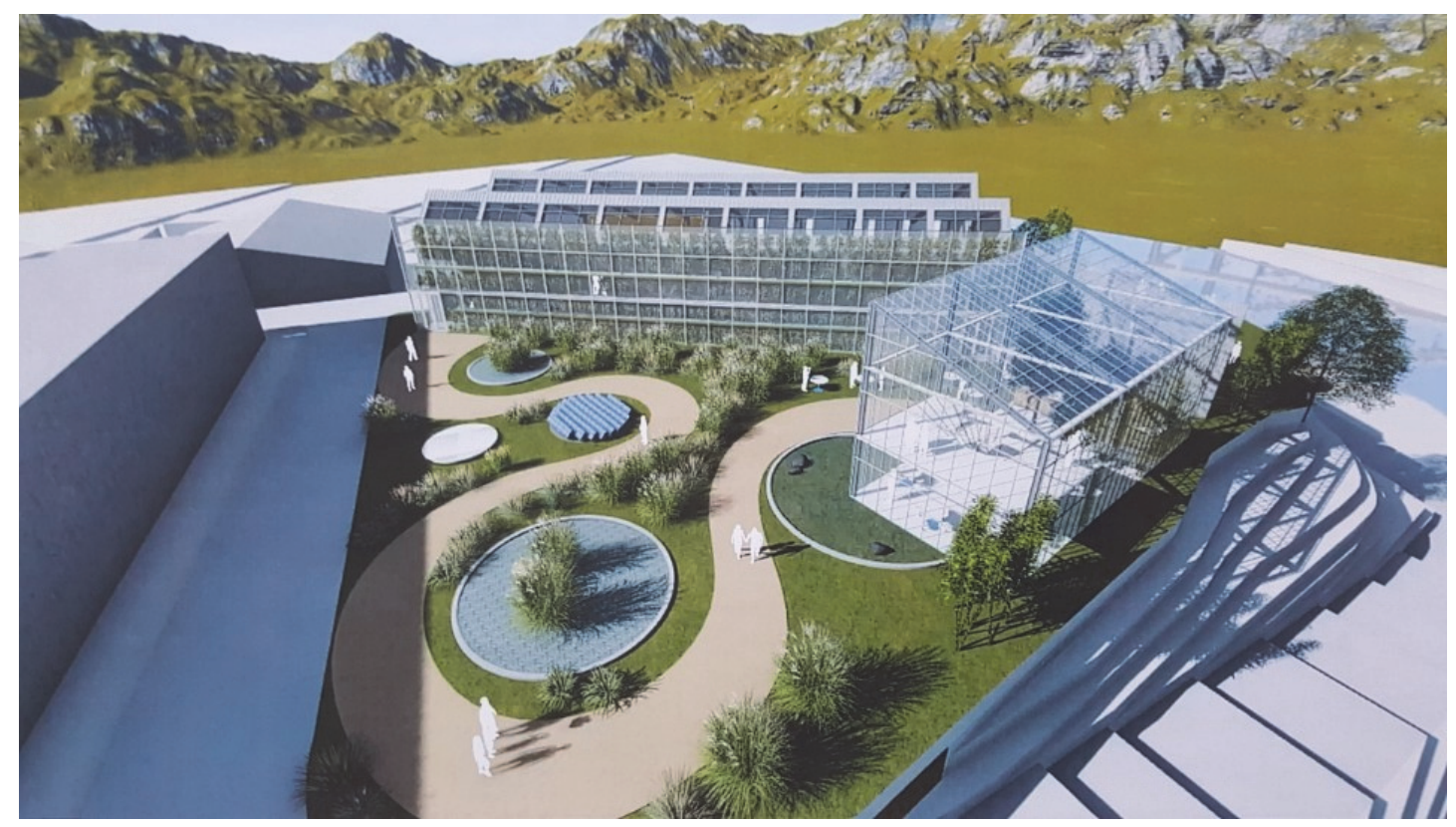


communication methods for the target audience by product, while continuing SNS marketing through earned media, which is a key contributing factor to SevenBräu's success. Additionally, in selecting communication channels and marketing contents, SevenBräu needs to consider recent trends among consumers such as the "Social - Local - Mobile" trend. To accomplish this, it is recommended to focus on 2-step communication, via opinion leaders or market mavens, rather than on 1-step communication, which directly connects the corporation with consumers. Also, interactions with consumers and customized communication need to be reinforced. An example is the Heineken consumer event utilizing the champion's league soccer matches. The event was extremely successful; it was mentioned repeatedly on SNS network, raising brand recognition while strengthening the association of Heineken and Soccer.

In the overall beer market, SevenBräu is an SME and latecomer, but it is a leading craft beer brewery with bigger production capacity than any other small breweries. Against this backdrop, SevenBräu would benefit in highlighting its position for its main target audience (including "For Me," "drinking alone," or "dining alone" generations) as a leader with large capacity, and as the first craft beer brewing company. In contrast, for those unfamiliar with craft beers, it is essential to stress SevenBräu's image as a "high-quality beer locally produced in small amounts" unlike the big-name domestic brewers.
To this end, key communication media should be selected differently to implement the strategy. In short, it is necessary to take advantage of online and mobile media to address the main target audience while raising brand awareness among traditional consumers through PR campaigns and other offline contacts.

\section{Conclusion and the Future of SevenBräu}

There is fierce competition in Korea's beer market where large domestic breweries dominate in an oligopolistic structure. However, latecomers such as imported beers and craft beers produced by small and medium-scale breweries are joining the competition. This competition has been accelerated by new trends such as consumers' growing interest in health and the resulting changes in drinking culture; demand for different beers according to changing dietary styles; increasing involvement in buying beer products; and diversification of the consumer base.

SevenBräu, launched in 2005 with craft beer "SevenBräu," became the first microbrewery in Korea to get a license for brewing beer and has been exploring new markets for beer by producing, distributing, and selling differentiated beers positioned as "high-quality craft beers locally produced in a traditional way" (with 
young consumers, aged 20 to 35, as the main target). Starting from the first product, IPA, SevenBräu created a unique assortment of ale and lager products with distinct flavor and aroma and distributed to wholesalers and retailers according to differentiated strategies. SevenBräu created brands named after regions and established an image of a region-friendly brand; focusing more on earned or owned media rather than on traditional channels; and implementing a communication strategy through corporate social responsibility (CSR) activities such as donation and community event support, as well as word-of-mouth and promotional campaigns.

SevenBräu has been showing remarkable growth with new brands that have regional characteristics and distinctive products. With a starting revenue of KRW 1.1 billion, its sales increased to KRW 3.2 billion in 2014, and KRW 6 billion in 2017. Its sales goal is KRW 13 billion in 2018 after a new factory was established in Yangpyeong; in addition to Hoengseong factory. It is scheduled to open an additional factory in 2019 and the two factories are estimated to each have an annual production capacity of 1,440 tons, which is translated into annual sales of KRW 10 billion each.

With the recent emergence of other small and medium-scale rivals, aggressive marketing by the competition, and the counterattack of existing big-name breweries, it is imperative for SevenBräu to address issues including brand hierarchy management and brand reinforcement, development of a value delivery network through network design, customizing communication strategies by product, and securing manufacturing facilities and operational competencies.

In the United States, an abandoned land and waste plant have been acquired and converted to a craft beer brewery, boosting the local economy. As the abandoned land became a tourist destination and nearby restaurants enjoyed indirect economic effects, the craft beer industry accounted for USD 68 billion, or KRW 73.6 trillion of the national economy, according to the American Craft Beer Association. Such growth of the craft beer market appears to be fueled by the tax break of the US government (Gang 2018). Based on the above, SevenBräu, being Korea's leading craft beer brand with regional based products, is expected to contribute significantly in stimulating domestic economy. Considering SevenBräu is committed to satisfying new consumer demands in the saturated beer market, increasing diversity, and exploring new markets overseas, it is expected that the company will lead the growth and change in the domestic beer market.

Like Boston Beer Company, which produces Samuel Adams, a representative American craft beer, SevenBräu is dedicated to creating the best beer with regional identity through continuous investment and development of a variety of products. Boston Beer Company is an accomplished enterprise with annual sales 
of USD 906.45 million in 2016 (Son 2018). SevenBräu can become Korea's Boston Beer Company if it keeps moving forward with active investment in developing new beers and regional brands.

〈Received November 17. 2018〉

〈Accepted December 3. 2018〉

\section{References}

Ahn, Jae-Man (2017), “The Blue House 'HOF meeting' effect, SevenBräu 'Craft beer' see a hike in sales," Joseon Biz, (accessed April 11, 2018), [available at http://biz. chosun.com/site/data/html_dir/2017/07/ 30/2017073000272.html].

Akpinar, Ezgi and Jonah Berger (2017), "Valuable Virality," Journal of Marketing Research, 54(2), 318-330.

Bae, Hyo-Geun (2017), "Status and Prospect of South Korean Craft Beer Market," Weekly KDB Report, 6-8.

Cho, Jong-Pyo, Dong-Min Lee, Jae-Seok Jeong and Jung-Hoon Moon (2014), "The factors of consumers' taste preferences for beer and change in attitude:Focusing on the Korean consumers' preference for imported beer," Journal of Foodservice Management, 17(3),7-30.

Cho, Sung-Hum (2018), “SevenBräu, 'Leisure and camping cultural town' completion of
Yangpyeong factory," Yonhap News, (accessed August 2, 2018), [available at http://www.yonhapnews.co.kr/bulletin/ 2018/07/30/0200000000AKR201807300834 00030.HTML].

Choi, Min-Yung (2018), "Why Domestic beers are not discounted like " 4 imported beer cans for 10,000 won',?" Kyunghyang Biz, (accessed April 12, 2018), [available at http://biz.khan.co.kr/khan_art_view. html?artid $=201801282142005 \&$ code $=920401]$.

Choi, Woo-Suk and Gyeong-Hwa Lee (2018), "Intensifying Competition in the Beer Market; Causes and Responses, and Credit Risk Changes of Beer Breweries," NICE Information Service, SPECIAL REPORT: NICE Issue, 2-13.

Gang, Gi-Joon (2018), "Craft Beer...revived dying cities in the US.," Money Today, (accessed April 11, 2018), [available at http://v.media. daum.net/v/20180304154651023?f=p].

Go, Gwang-Cheol(Ed.) (2018), “[2018 Korea First Brand Awards] Gangseo - Dalseo, Korea's first craft beer brewery, SevenBräu," Hankyung, (accessed April 11, 2018), [available at http://news.hankyung.com/ article/2018011580811].

Hwang, Sang-Wook (2018), "SevenBräu Beer • Korean Film Actors Association concluded a business agreement," Busan Daily, (accessed April 12, 2018), [available at http:// news20.busan.com/controller/newsController. jsp?newsId $=20180104000098]$. 
Kotler, Philip T. and Kevin Lane Keller (2012), Marketing Management, Boston: Pearson. Lee, Do-Yeon (2017), “SevenBräu, chosen by the Blue House 'HOF' Meeting... 'Zero irregular workers' beer," Yonhap News, (accessed April 12, 2018), [available at http://www.yonhapnews.co.kr/bulletin/ 2017/07/27/0200000000AKR201707271607 00030.HTML].

Lee, Gi-Hwan (2017), "Anti-competitive Effect of Discriminatory Tax Base of the Beer Market," KERI Insight, 16(39), 1-32.

Lee, Gyeong-Hwa (2018), "2018 Risk Evaluation of the Liquor Industry in 2018," NICE Information Service, 1-13.

Lee, Jae-Heon (2016), "20s hon-meak generation's beer and snack consumption trend survey report," Daehaknaeil 20's lab, (accessed August 2, 2018), [available at https:// www.20slab.org/archives/13844].

Narver, John C. and Stanly F. Slater (1990), "The effect of a market orientation on business profitability," Journal of Marketing,
54(4), 20-35.

Noh, Jung-Yeon (2017), “Big-name beers, challenged by imported '.craft beers," Kyunghyang Biz, (accessed April 12, 2018), [available at http://biz.khan.co.kr/khan_ art_view.html?artid $=201704091720001 \&$ code $=920401]$.

Son, Duk-Ho (2018), “'UUS Craft beer company” reaching KRW 900 billion in annual sales after 30 years in business," Economy Joseon, (accessed April 10, 2018), [available at http://m.post.naver.com/viewer/postView. nhn? volumeNo $=13253395 \&$ memberNo $=$ 35002835].

Trade Statistics of Korea Customs Service (2018), (accessed April 11, 2018), [available at https://unipass.customs.go.kr:38030/ ets/index.do].

Woo, Soo-Yeon (2017), “'President's Beer' SevenBräu, making crowdfunding investors smile," Newspim, (accessed April 11, 2018), [available at http://www.newspim.com/ news/view/20170731000048]. 